\title{
ZAGREBELSKY, Gustavo (2007) Imparare democrazia. \\ Turín: Einaudi, 182 pp.; y \\ ZAGREBELSKY, Gustavo (2007) La virtù del dubbio. \\ Intervista su etica e Diritto (a cura di Preterossi). \\ Roma: Geminelle, Laterza, 166 pp.
}

Gustavo Zagrebelsky (San Germano Chisone, 1943) ha sido calificado por algún autorizado contemporáneo como uno de los "más inteligentes y cultos constitucionalistas italianos" ${ }^{1}$. Y no sin razón, pues el ex miembro de la Corte Constitucional italiana (1995-2004) y Profesor de la Facultad de Derecho de la Universidad de Turín, es autor de uno de las más influyentes obras de la teoría constitucional de la segunda mitad del siglo XX. Se trata del Diritto mitte o el Derecho dúctil, en su versión castellana $^{2}$, trabajo que ha sido seguida por importantes textos, tales como Il "crucifuge!" e la democrazia (Einaudi, Turín, 1995), La domanda di giustizia (con Carlo Maria Martini Card., Einaudi, 2003), La leggenda del grande inquisitore (Morcelliana, Brescia, 2003), Principî e voti (Einaudi, Turín, 2005) ${ }^{3}$, Diritti e Costituzione nell'Unione Europea (a cura di, Laterza, Roma, 2003), Norberto Bobbio tra Diritto e politica (con M. Salvadori y R, Gustini, Laterza, Roma, 2005), Essere delle istituzioni (Editoriale Scientifica, Nápoles, 2005) y Giuda. Il tradimento fedele (Morecelliana, Brescia, 2007).

La producción bibliográfica del Profesor Zagrebeslky es amplia, pasando por la manualística, las obras científicas y la ensayística. En ellas hay ciertos temas recurrentes, tales como la justicia constitucional, la democracia, la teoría de la Constitución y del Derecho, y perspectivas frecuentes, como es el permanente diálogo con la historia y con las religiones (la publicación con el Card. Martini fue un estupendo ejercicio de ello). Las dos obras que se comentan en esta oportunidad se encuentran entre ambos extremos, pues en cierto modo son un manual y, en otro, un ensayo. En todo caso, el eje que vertebra a ambos trabajos es el mismo: el concepto e implicaciones de la democracia.

Imparare democrazia es, ante todo, un ensayo con vocación de instrumento de educación cívica, que pretende resumir en diez proposiciones el sentido de lo que el autor califica como un "concepto idolátrico omnicomprensivo" (pág. 3) que adolece de una profunda y auténtica pedagogía. En una época en que la democracia es una suerte de comodín

GrossI, Paolo (2007) Mitologie giuridiche della modernità. Milan: Giuffrè, p. 65.

ZAGRebelsky, Gustavo (1992) Il diritto mitte. Torino: Einaudi, de la cual hay traducción al castellano (de M. Gascón, Trotta, Madrid, 2003).

3 Vid. mi reseña en Estudios Constitucionales 4/2 (2006), pp. 729-732. 
conceptual, que vale tanto para una cosa como para su opuesto, que flota en un ambiente de creciente apatía de participación, el librito de Zagrebelsky representa un estupendo ejercicio de síntesis pedagógica y de difusión del espíritu democrático, que (como decía Montesquieu) es fundamental para el funcionamiento de tal sistema. Como enseñaban los clásicos, las buenas reglas no son suficientes, hacen falta también buenos hombres. Dicho de otro modo, un pueblo no educado en la democracia, no es un buen practicante de la democracia.

Los diez "puntos" que estructuran este decálogo, constituyen una suerte de "contenidos mínimos necesarios del ethos democrático" (pág. 14), y se expresan del siguiente modo: I) la fe en algo; II) el cuidado de las personalidades individuales; III) el espíritu del diálogo; IV) el espíritu de la igualdad; V) la apertura bacia el que posee una identidad diferente; VI) la desconfianza bacia las decisiones irremediables o irreversibles; VII) la actitud experimental; VIII) la conciencia de la mayoría y de la minoría; IX) la actitud altruística; y X) el cuidado por las palabras. Este decálogo es completado con una fina selección de textos sobre la democracia (Herodoto, Aristófanes, Cicerón, Montesquieu, de Tocqueville, Brecht, Orwell, Arendt, Bobbio y Carillo).

Por su actualidad en la sociedad chilena, quisiera detenerme en algunas proposiciones de este decálogo.

La fe en algo. Nuestra historia republicana, especialmente la que sigue al restablecimiento de la democracia durante los noventa, nos enseña que cuanto más lejos están los tiempos difíciles más se reduce la fe en la política y en la democracia. A fines de los ochenta, parafraseando a Gabriela Mistral, "todos queríamos ser demócratas". Eran pocos los que no corrían a inscribirse en los registros electorales. Ahora, son pocos los que caminan, y, de correr, ni hablar. El autor identifica la clave de este grave problema en la necesidad de creer en algo y en la de dialogar con el resto sobre ello. La democracia supone creer en algo, y tanto el pretendido absolutismo de ciertas verdades como el completo nihilismo o escepticismo representan amenazas para esa forma de gobierno. Es difícil, en este punto, no encontrarle la razón al autor. En efecto, la historia chilena de principios de los setenta es una estupenda muestra que confirma ese aserto: cuando la mayoría cree en algo, el terreno para la praxis política está abonado para la democracia, pero cuando falla la virtud o capacidad del diálogo prudente -la $\varepsilon v \beta o \lambda \iota \alpha$ de los clásicos- fallan también todas las posibilidades de continuidad del sistema democrático. Como dice el autor "si no se tiene fe en nada, ¿para qué defender una forma de gobierno respecto de otra?". Por ello, hay una importante cuestión asunto que no puede quedar sin respuesta: “¿cómo se enseña a ser democráticos, esto es, a creer de verdad en la democracia?” (pp. 39 y ss.). La única respuesta que se atreve a formular el autor, tras pensar y volver a pensar ("pensando e ripensando", 42), es el "respeto por sí mismo". La 
democracia sería "la única forma de gobierno político que respeta mi dignidad, que me reconoce la capacidad de discutir y decidir sobre mi vida política. Todos los otros regímenes no me conceden este reconocimiento, me consideran indignos de autonomía fuera del cerco que constituyen mis relaciones puramente familiares y privadas" (pp. 42-43). Este convencimiento implica asumir que la democracia es, más allá de un procedimiento -en las visiones minimalistas o procedimentales- o una entre varias formas de gobierno, un empeño, un "trabajo". Y como todo trabajo, ella cansa. Como enseña nuestra historia reciente: "la opresión despótica genera reacción y rebelión. La democracia, en cambio, cansancio". La única forma de combatir ese cansancio es estimulando el interes por la polis, el altruismo.

El cuidado de las personalidades individuales y el cuidado del lenguaje. Las modas afirman o reafirman la pesonalidad de quien las sigue frente a quienes se resisten a ellas o, simplemente, siguen a otras. Pero al mismo tiempo, esas modas diluyen la identidad del individuo dentro del grupo que las fija. Sobre este tema, el autor pone el dedo y toda su mano en una herida de buena parte de las sociedades contemporáneas, especialmente de sus segmentos más jóvenes, la pérdida de la identidad, la difusión del pensamiento único, el empobrecimiento del lenguaje y la desvalorización del respeto a través de la palabra. Para el autor "la democracia que quiere preservarse de la degeneración democrática debe cuidar al máximo el grado de originalidad de cada uno de sus miembros y combatir [el autor no sugiere cómo] la pasiva adhesión a las modas" (p. 19). La reducción de los niveles de lectura de las actuales generaciones, acompañada de la escasa complejidad linguística que exige la comunicación electrónica y telefónica, están conduciendo a un progresivo empobrecimiento del lenguaje que, como pronosticó George Orwell en 1984, es una de los mejores enemigos de la democracia. Tampoco es amiga de la democracia, o por lo menos tampoco es un estímulo para una verdadera educación democrática, la extraordinaria difusión por los medios de comunicación social de las gracias y desgracias de la farándula, o de la vida privada y las disputas de quienes consienten ponerse bajo la mirada de un Big Brother al mejor estilo orwelliano. Hablar mal, en el decir de los clásicos, hace daño al espíritu.

Ahora bien, La virtù del dubbio transcribe las respuestas de Zagrebelsky a un extenso interrogatorio de Geminello Preterossi, Profesor de Derechos fundamentales y Filosofía del Derecho en la Facultad de Derecho de la Universidad de Salerno. Las preguntas, muchas veces redactadas en los largos períodos que caracterizan algunos escritos italianos, se siguen de agudas respuestas (que algunas veces se resumen en un simple "no") que vienen a complementar y facilitar la comprensión de escritos anteriores sobre la política, la Constitución, el Derecho o la democracia. La temática es variada y comprende Ios relatos autobiográficos que explican la inclina- 
ción del autor por el Derecho constitucional ("Inclinazione al diritto costituzionale"), la relación entre el Derecho y la justicia ("Diritto e giustizia"), los alcances de su teoría sobre el Derecho dúctil ("Il diritto mitte"), la función de la constitución frente al binomio pluralismo/multiculturalismo ("Pluralismo e multiculturalismo") y las posibilidades de una unidad política mundial ("Civitas maxima' o 'res publica universalis'?").

El valor de La virtù del dubbio reposa en dos aspectos. El primero de ellos, ya presentado en Imparare democrazia, es la exposición de la desconfianza hacia el dogmatismo que deriva de quienes, en nombre de la Constitución, "se llenan la boca de 'valores' " (p. 25) o de una presunta ley natural que, a juicio del autor, solo siembra el camino de nuevos conflictos. La primera crítica recuerda la discusión alemana sobre la concepción de la Constitución, al menos en lo que a los derechos fundamentales concierne, como un orden objetivo de valores ${ }^{4}$, de profunda influencia en la teoría y prácticas españolas ${ }^{5}$ y, desde esa fuente, en la teoría constitucional nacional. Este dogmatismo, no solo es perjudicial para la democracia (que, como ya se dijo, presupone el diálogo) sino también para el concepto de Constitución. Aquí aparece el segundo valor del La virtù del dubbio, como texto explicativo auxilio para la correcta inteligencia del Diritto mitte.

Luego de expresar algunas dudas sobre el extraordinario éxito del Derecho dúctil ${ }^{6}$, Zagrebelsky reitera su confianza en el Derecho positivo. En efecto, aunque el autor ha criticado durante toda su vida los excesos del discurso positivista (las anécdotas sobre la influencia de Bobbio durante sus años de estudiante son notables $)^{7}$ no hay, en la obra de Zagrebelsky, una completa huida del metodo positivista. Recuérdese la frase de Il Diritto mitte, "la Constitución no es Derecho natural sino más bien la manifestación más alta del Derecho positivo"8. Por lo que concierne al

4 La influencia de los trabajos de Rudolf Smend y de la sentencia Lïth del Tribunal Constitucional alemán (15 de enero de 1957, en BVerGE 7, 198) son bastante conocidos. Herdegen, M. (1998) "Natural Law, Constitutional Values and Human Rights". Human Rights Law Journal 19/2-4, pp. 39 y ss.

5 Véanse, por ejemplo, las siguientes sentencias del Tribunal constitucional español: 5 / 1981, 21/1981, 8/1983, 67/1982, 53/1985, 35/1987, entre otras.

6 "Me alegra de este éxito relativo, sin embargo es un éxito que a menudo depende de una cierta superficialidad de la lectura, lectura que, sospecho, en no pocos casos no ha ido más allá del título". Zagrebelsky (2007b) 90.

"En 1969, en la discusión de los títulos para la docencia libre (...), debía tratar no recuerdo qué problema, quizá alguno sobre la costumbre constitucional, y sostuve una posiciốn que no era kelsesianamente ortodoxa. Me pareció casi completamente natural excusarme, justificarme por la libertad que me estaba tomando, cuando el Profesor Guarino, Giuseppe Guarino, con una gran sonrisa me sorprendió con un: '¿Y entonces? ¿Qué hay de malo?" ". A esta pregunta, el joven Zagrebelsky respondió con "Mah, sa, vengo da Torino" ("sabe, vengo de Turín"). 
carácter de su teoría, en La virtù del dubbio Zagrebelsky se preocupa de aclarar que el Derecho dúctil no es una doctrina, en el sentido que la obra no pretende indicar ideales constitucionales ni las herramientas para alcanzarlos. Por el contrario, en palabras del autor, es un "intento de teoría" (p. 91) simplemente descriptiva de lo que el Derecho es, sobre la base de datos histórico-constitucionales concretos, y que solo persigue describirlos, comprenderlos, ponerlos en orden, encontrar los nexos, indicar las condiciones, las consecuencias e implicaciones, etc. (pág. 91). Para el autor la ductilidad o la templanza (en las diversas traducciones que puede tener la palabra mittezza) es un atributo del Derecho que emana de su condición de herramientas de convivencia en un contexto pluralista que no admite absolutos (salvo el propio pluralismo de los valores y su necesidad de confrontación leal)9. "Todo 'gran tema' del Derecho constitucional moderno se encuentra estructuralmente caracterizado por la presencia de elementos constitucionales que, para poder coexistir, deben ser relativizados unos con otros, es decir, deben ser (...) templados o moderados"10.

El intento teorizante y descriptivo, sin embargo, no oculta una preferencia del autor, para quien a la teoría se agrega (sin sustituirla) una doctrina o una apología, según la cual él confiesa preferir el Derecho dúctil frente al Derecho "agresivo" inútil para ordenar comunidades pluralistas.

\section{MANuel A. Núñez Poblete*}

ZAGREBELSKY (1992) 11.

ZAGREBELSKY (1992) 17.

Doctor en Derecho, Universidad de Santiago de Compostela (España). Profesor de Derecho Constitucional de la Universidad Católica del Norte (Chile). Correo electrónico: manunez@ucn.cl 
